\title{
A voltage electrical distance application for power system load shedding considering the primary and secondary generator controls
}

\author{
Le Trong Nghia', Quyen Huy Anh², Phan Thi Thanh Binh ${ }^{3}$, N Thai An ${ }^{4}$, P H Hau \\ 1,2,4,5 Department of Electrical and Electronics Engineering, HCMC University of Technology and Education, Vietnam \\ ${ }^{3}$ Department of Electrical and Electronics Engineering, HCMC University of Technology, Vietnam
}

\begin{tabular}{l} 
Article Info \\
\hline Article history: \\
Received Feb 2, 2019 \\
Revised Apr 22, 2019 \\
Accepted May 4, 2019 \\
\hline
\end{tabular}

Keywords:

Frequency control

Load shedding

Primary control

Secondary control

Voltage electrical distance

\begin{abstract}
This paper proposes a method for calculating the minimum amount of power load needed to shed and distributing it for each load bus in order to recover the frequency back to the allowable range. Based on the consideration of the primary control of the turbine governor and the reserve power of the generators for secondary control, the minimum amount of load shedding was calculated in order to recover the frequency of the power system. Computation and analysis of the voltage electrical distance between the outage generator and the loads to prioritize distribution of the amount power load shedding at load bus positions. The nearer the load bus from the outage generator is, the higher the amount of load shedding will shed and vice versa. With this technique, a large amount of load shedding could be avoided, hence, saved from economic losses, and customer service interruption. The effectiveness of the proposed method tested on the IEEE 37 bus 9 generators power system standard has demonstrated the effectiveness of this method.
\end{abstract}

Copyright $@ 2019$ Institute of Advanced Engineering and Science. All rights reserved.

\section{Corresponding Author:}

Le Trong Nghia,

Department of Electrical and Electronics Engineering,

HCMC University of Technology and Education,

01Vo Van Ngan street, Thu Duc district, Ho chi minh city, Vietnam.

Email: trongnghia@ hcmute.edu.vn

\section{INTRODUCTION}

The imbalance active power between the generation and the load demand causes a decrease the frequency in the power system. The monitoring and control system will immediately implement the control solutions to restore the frequency back to the allowable value, and improve the power system stability [1]. In [2], the primary and secondary control power plants are set by automatic controlled equipment or the power system operator. After implementing all possible control solutions that the system's frequency has not yet recovered to the allowable value, the most efficient method is to reduce the load [3]. The underfrequency load shedding relay (UFLS) is the traditional load shedding method used quite commonly in the current power system. In [4], the relays are set to operate whenever the frequency drops to a specified level and a fixed amount of load power is shed to restore the frequency. Using under frequency load shedding relay to disconnect the load bus will make in insufficient or excessive load shedding and take a long time to restore the frequency back to stable. This result will make damages for the suppliers and customers using the system's power. The authors in $[5,6]$ showed methods to estimate the amount load shedding, which based on the frequency reduction, or the rate of change of frequency (ROCOF). The combination of intelligent load shedding methods has also been studied and developed such as Artificial Neural Network (ANN) [7], fuzzy logic algorithms [8], genetic algorithm (GA) [9] or particle swarm optimization (PSO) algorithm. These methods minimize the load shedding costs at steady state operation of power system [10]. 
A good load shedding program should be shed with the minimum number of load buses and as quickly as possible, and must meet the system's permissible frequency conditions. On the other hand, in large disturbances of the power system, frequency decay is often associated with voltage decay. Voltage decay at load buses reduces system load, therefore the reduction in frequency is slowed and the actual load shedding by UFLS is reduced relative to the level required [11-13]. In most practical conditions, the amount of load shedding may be more or less the amount of power the system needs to maintain the frequency, which may lead to cost losses as well as affects the objects that the system serves.

This paper presents a new method of load shedding to minimize the amount of load shedding power. The load shedding strategies based on the voltage electrical distance, to find out the priority and distribute the amount of load shedding power for each load bus. For load buses, the closer the load bus from the outage generator is, the higher the amount of load shedding will shed and vice versa.

\section{METHODOLOGY}

\subsection{Overview the power systerm frequency responds}

The basic concepts of speed governing are best illustrated by considering an isolated generating unit supplying a local load as shown in Figure 1.

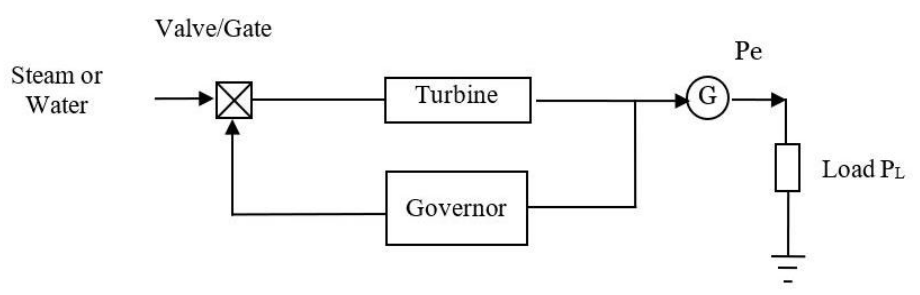

Figure 1. Generator provides independent load

The power system loads are a composite of a variety of electrical devices. For resistive loads, such as lighting and heating loads, the electrical power is independent of frequency. In the case of motor loads, such as fans and pumps, the electrical power changes with frequency due to changes in motor speed. The references $[14,15]$ showed the overall frequency-dependent characteristic of a composite load:

$$
\Delta P_{e}=\underset{\text { Nonfrequency-sensitive-load-change }}{\Delta P_{L}}+\underset{\text { Frequency-sensitive-load-change }}{D \Delta \omega}
$$

where: $\Delta P_{L}$ - is the load component does not depend on frequency, eg heat load, lighting, ...; $D \Delta \omega_{r}-$ the change in load depends on the change of frequency, eg, motors, pumps, etc; $\Delta P_{e}$ Deviation of power change; $\Delta \omega_{r}$ : Deviation of angle speed change; $\mathrm{D}$ : The percentage change in load with percentage of change in frequency varies, $\mathrm{D}$ is from $1 \div 2 \%$.

The transfer function block diagram reflects the relationship between the load change and the frequency taking into account the governor characteristic, the prime mover and the load response shown in Figure 2 [16]. The effects of the governor speed droop and the frequency of load on the net frequency as shown in Figure 3.

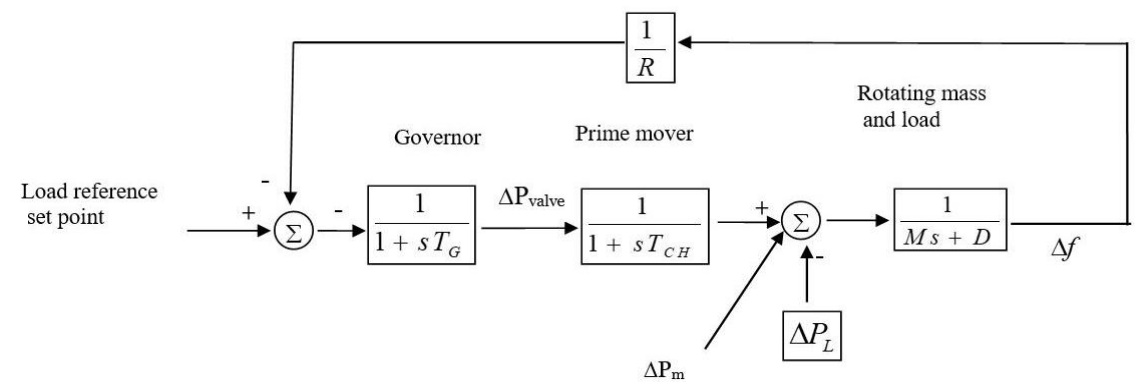

Figure 2. The transfer function block diagram describes the relationship between the load changes and frequency 


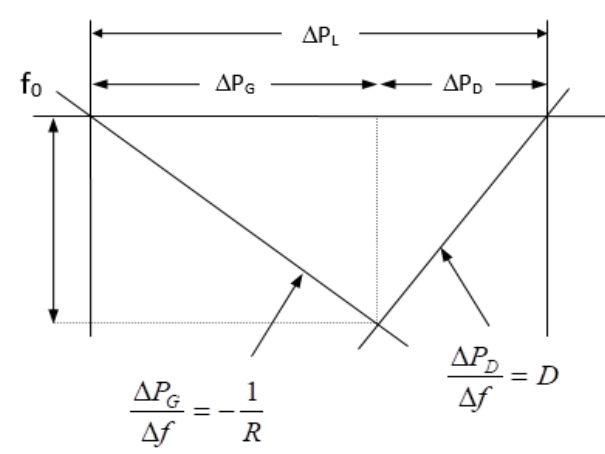

Figure 3. The effects of the governor speed droop and the frequency of load on the net frequency [17]

The transfer function relating the load change, $\Delta P_{L}$, to the frequency change, $\Delta \omega$, is

$$
\Delta f(s)=\Delta P_{L}(s)\left[\frac{\frac{-1}{M s+D}}{1+\frac{1}{R}\left(\frac{1}{1+s T_{G}}\right)\left(\frac{1}{1+s T_{C H}}\right)\left(\frac{1}{M s+D}\right)}\right]
$$

where: $\mathrm{K}_{\mathrm{G}}$ the amplification stage; $\omega_{\text {ref }}$ reference speed; $\mathrm{T}_{\mathrm{CH}}$ "charging time" time constant; $\Delta P_{\text {valve }}$ per unit change in valve position from nominal; Ms angular momentum of the machine in Laplace transform; $\mathrm{R}$ is equal to pu change in frequency divided by pu change in unit output; it is characteristic for the sliding speed adjustment; $R=-\Delta f / \Delta P$

The purpose of system simulation in the form of a transfer function is to calculate the time response of the frequency deviation when the load change step is $\Delta \mathrm{P}_{\mathrm{L}}$. From the above description, frequency deviation in steady state it means the values of the transfer function is determined for $\mathrm{s}=0$ :

The steady-state value of $\Delta f(s)$ may be found by:

$$
\Delta f \text { steady state }=\lim [s \Delta f(s)]=\frac{-\Delta P_{L}\left(\frac{1}{D}\right)}{1+\left(\frac{1}{R}\right)\left(\frac{1}{D}\right)}=\frac{-\Delta P_{L}}{\frac{1}{R}+D}
$$

when the power system has multiple generators with independent governors, the frequency deviation in steady state is calculated according to (4).

$$
\Delta f=\frac{-\Delta P_{L}}{\frac{1}{R_{1}}+\frac{1}{R_{2}} \ldots+\frac{1}{R_{n}}+D}
$$

Set $\beta=\left(\frac{1}{R_{e q}}+D\right)^{-1}$ is the general frequency response characteristic of power system. It includes the adjustment characteristics of turbine mechanical power and load. From (4), obtain:

$$
\Delta f=-\Delta P_{L} \cdot \beta
$$

\subsection{Primary and secondary frequency control in the power system}

Primary frequency control is an instantaneous adjustment process performed by a large number of generators with a turbine power control unit according to the frequency variation. Secondary frequency control is the subsequent adjustment of primary frequency control achieved through the AGC's effect (Automatic Generation Control) on a number of units specifically designed to restore the frequency back to its nominal value or otherwise, the frequency-adjusting effects are independent of the governor's response called the secondary frequency control. The process of the primary and secondary frequency control was shown in Figure 4.

A voltage electrical distance application for power system load shedding considering ... (Le Trong Nghia) 


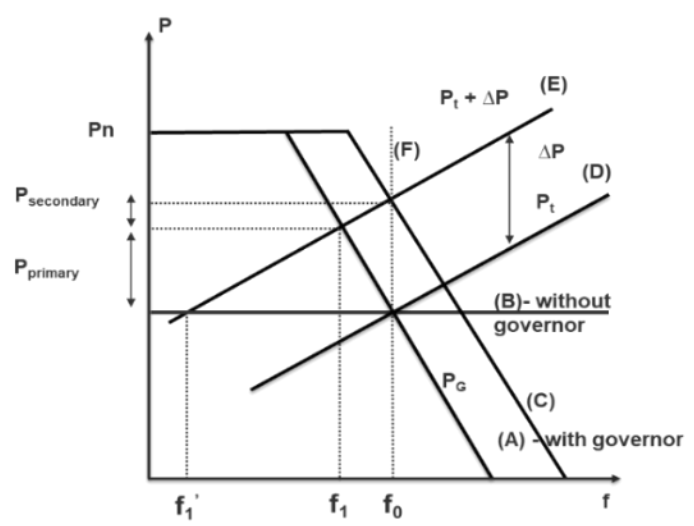

Figure 4. The relationship between frequency deviation and output power deviation

Characteristic line (A) shows the effect of the governors: change the turbine power according to the change of frequency. In balance mode, the intersection of the generator characteristic line (A) with the frequency characteristic of the load line (D) determines the frequency $\mathrm{f}_{0}$ equal $50 \mathrm{~Hz}(\mathrm{or} 60 \mathrm{~Hz}$ ). When the load increases $\Delta \mathrm{P}_{\mathrm{L}}$, the new characteristic line will be line $(\mathrm{E}): \mathrm{P}_{\mathrm{t}}+\Delta \mathrm{P}$

In addition, the intersection of the generator characteristic line (A) with the new load characteristic line (E) defines the new frequency $\mathrm{f}_{1}$. Here, $\mathrm{f}_{1}<\mathrm{f}_{0}$. Compared to the case where the generator does not have a governor, characteristic line $(B)$, it is clear that: $f_{1}<f_{0}$. According to the characteristic line (A) of the generator unit, the governor does not prevent the frequency reduction: $\Delta f=f_{0}-f_{1}$ However, because the generator has the governor, it has helped to limit the large deviation of the frequency. Compared with the case the generators do not have a governor (B), the intersection with the new characteristic line of the load (E) will determine the frequency $f_{1}: f_{1}<f_{1}<f_{0}$. Thus, the governor of the generator unit has the effect of reducing the large change of frequency known as the primary frequency controller. The efficiency of the primary frequency control depends on the slope of the speed-droop characteristic of the generator units. In the ideal case, the adjusting characteristic line $(\mathrm{F})$ of the generator unit is vertical line; the frequency will not change until the power limit of the generator unit $\mathrm{P}_{\mathrm{n}}$.

The above characteristics of the primary adjustment process lead to the need for external intervention (by the automatic control device or by the power system operators) - that is the secondary frequency control process. The secondary adjustment characteristic is represented by the simultaneous shifting of the characteristic line (A) into the characteristic line (C) of the generator unit, with the slope unchanged. This adjustment is equivalent to the creation of a static vertical adjustment characteristic line (F). Thus, the secondary adjustment is within the rated power range of the generator unit to restore and maintain the frequency within the allowable value.

\subsection{Calculate the minimum load shedding power considering the control characteristic of turbine mechanical power and load.}

In the $60 \mathrm{~Hz}$ power system, the frequency deviation allowed $\Delta \mathrm{f}_{\mathrm{p}}$ is $0.3 \mathrm{~Hz}\left(\Delta \mathrm{f}_{\mathrm{p}}=-0.3 \mathrm{~Hz}\right)$. In the case of the power deficiency or imbalance between the source and the load causing the frequency difference, the frequency control will be implemented in the following order: primary control, secondary control. When the reserved power is used for secondary control and the frequency has not been restored to the permitted value, the load will be shed. Thus, from equation (5), the relationship between the permissible change in frequency, the amount of secondary control power and the minimum load shedding power $P_{L S m i n}$ is calculated according to the proposed formula below:

$$
\Delta f_{p}=-\beta \cdot\left[\Delta P_{L}-\left(\Delta P_{\text {Secondary control }}+P_{L S \text { min }}\right)\right]
$$

In this case, if $\left(\Delta \mathrm{P}_{\text {Secondary control }}+\Delta \mathrm{P}_{\mathrm{LS} \text { min }}\right)<\Delta \mathrm{P}_{\text {Sacondary max }}$, then $\Delta \mathrm{P}_{\mathrm{LSmin}}=0$, otherwise the minimum power load shedding is calculated by the equation (7):

$$
P_{L S \min }=\Delta P_{L}-\left(\frac{-\Delta f_{p}}{\beta}\right)-\Delta P_{\text {Secondary Max }}
$$

where: $\Delta \mathrm{f}_{\mathrm{p}}$ is the permissible change in frequency $(\mathrm{pu}) ; \mathrm{P}_{\mathrm{LSmin}}$ is the minimum amount of power required to shed $(\mathrm{pu}) ; \Delta \mathrm{P}_{\text {Secondary control }}$ is the amount of secondary control power addition to the system. 


\subsection{The voltage electrical distance (VED)}

After calculating the minimum amount of load shedding power required, the next issue determines the distribution the amount of load shedding power at load buses. The goal is to focus priority on load shedding at around or near the outage generators location. To do this, the concept of the voltage electrical distance between two buses is used. The voltage electrical distance between the outage generator and load buses is calculated using the proposed process in [18], which is performed as follows:

$$
\alpha_{\mathrm{ij}}=\frac{X_{\mathrm{ij}}}{X_{j j}} \neq \alpha_{j i}=\frac{X_{\mathrm{ij}}}{X_{i i}}
$$

The equation (9) can be taken as a definition of the voltage electrical distance between two node $\mathrm{i}$ and $\mathrm{j}$.

$$
D_{V}(i, j)=D_{V}(j, i)=-\log \left(\alpha_{\mathrm{ij}} * \alpha_{j i}\right)
$$

The general equation calculates the amount of load shedding distribution at nodes according to the voltage electrical distance:

$$
P_{L S i}=\frac{D_{V, e q}}{D_{\mathrm{V}, m i}} \cdot P_{L S \text { min }}
$$

where, $\mathrm{m}$ is the number of generator bus; $\mathrm{i}$ is the number of load bus; $\mathrm{P}_{\mathrm{LSi}}$ the amount of load shedding power for the $\mathrm{i}$ bus (MW); $\mathrm{P}_{\mathrm{LS} \text { min }}$ the minimum amount of load shedding power to the restore of frequency back to the allowable value $(\mathrm{MW})$; $\mathrm{D}_{\mathrm{V} \text {,mi }}$ : the voltage electrical distance of the load to the $\mathrm{m}$ outage generator; $\mathrm{D}_{\mathrm{V}, \mathrm{eq}}$ : the equivalent voltage electrical distance of all load buses and generator.

\section{CASE STUDIES - SIMULATION AND RESULTS}

The effectiveness of the proposed method is tested on the IEEE 37 bus 9 generators system [19] which is shown in Figure 5. The Bus-31 are considered as the swing bus. Total the active power and the reactive power of the system are 1046.52 MW and 226.47 MVAR respectively under normal operating conditions. The maximum active power and reactive power of the system are $1087 \mathrm{MW}$ and 449 MVAR. $\mathrm{S}_{\text {base }}=100 \mathrm{MVA}$ for this test system. The control solutions minimize the amount of load shedding and maintain steady-state frequency from 59.7 to $60 \mathrm{~Hz}$. To test the effectiveness of the proposed method, the outage situations of the generator units are calculated, simulated and tested the parameters. In the case of calculations and simulations, the spinning reserved power to control the secondary frequency is also considered. All test cases are simulated on PowerWorld GSO 19 software. The results are compared with the results of the traditional load shedding method using under frequency load shedding relay.

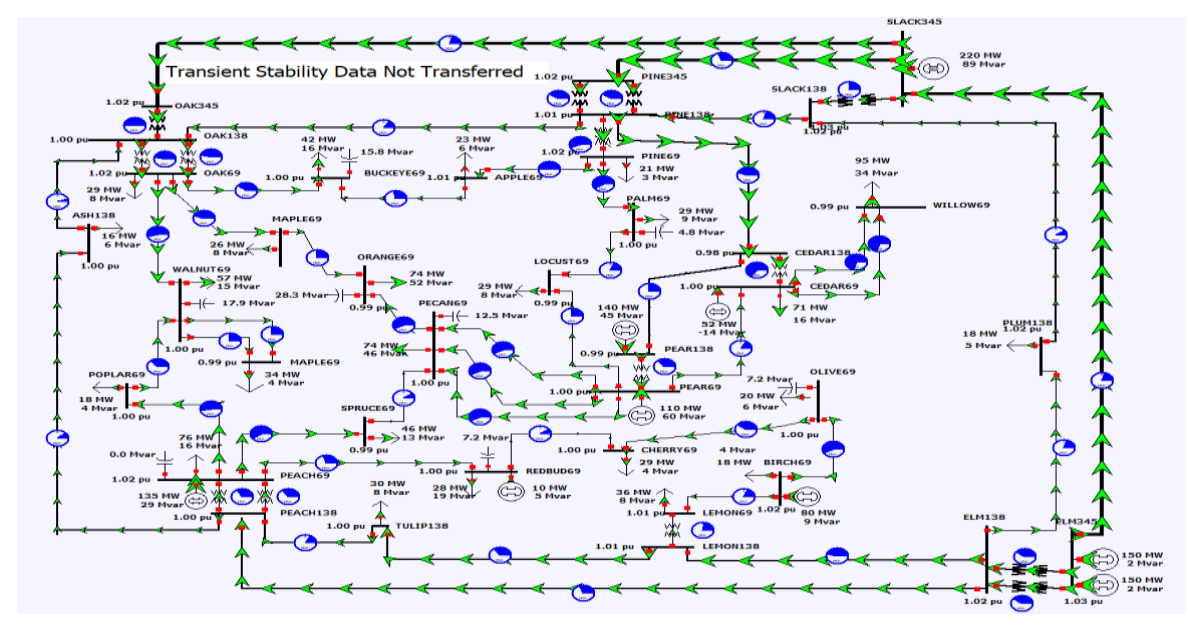

Figure 5. The IEEE 37 bus 9 generators test system 
Apply the (5), (6), (7) equation calculate the system frequency, the amount of primary and secondary control power and the amount of load to be shed. The results of the computation of the outage generator situations are shown in Table 1.

Table 1. The outage generators cases

\begin{tabular}{cccccc}
\hline Name of Gen. Bus & $\begin{array}{c}\text { Frequency } \\
(\mathrm{Hz})\end{array}$ & $\begin{array}{c}\text { In the allow } \\
\text { range }\end{array}$ & $\begin{array}{c}\text { The primary control } \\
\text { power value (MW) }\end{array}$ & $\begin{array}{c}\text { The secondary control } \\
\text { power value (MW) }\end{array}$ & $\begin{array}{c}\text { The amount of load } \\
\text { shedding (MW) }\end{array}$ \\
\hline REDBUD & 59.97 & Yes & 10 & 0 & 0 \\
ELM345\#1 & 59.56 & No & 150 & 15.5 & 30.77 \\
ELM345\#2 & 59.56 & No & 150 & 15.5 & 30.77 \\
PEACH69 & 59.62 & No & 112.31 & 0 & 13.89 \\
CEDAR69 & 59.86 & Yes & 52 & 0 & 0 \\
BIRCH69 & 59.79 & Yes & 80 & 31.07 & 0 \\
PEAR138 & 59.6 & No & 140 & 0 & 0 \\
PEAR69 & 59.7 & Yes & 110 & & 0 \\
\hline
\end{tabular}

In the test example, the sudden disconnection of the ELM345\#1 generator (bus 28) is simulated. Applying the (5) calculates the stable frequency value when the ELM345\#1 generator (bus 28) disconnects from the system. The frequency value is $59.37 \mathrm{~Hz}$, and shows in Figure 6.

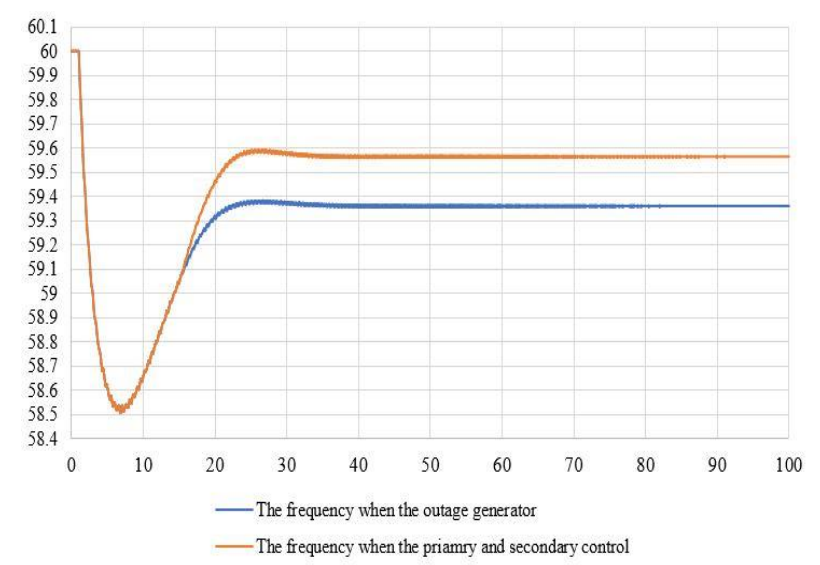

Figure 6. The frequency of the system when the ELM345\#1 generator disconnects

After the ELM345\#1 generator suddenly disconnects, the frequency value is less than the allowable value. Therefore, the primary control and secondary frequency control which presented in section 2.2 for frequency recovery should be implemented. The primary control process is done automatically by the turbine governor after the ELM345\#1 outage generator. The value of the primary control power of each generator turbine is shown in Table 2.

Table 2. The value of the primary control power of the generators

\begin{tabular}{lc}
\hline Generator & $\begin{array}{c}\text { The increased primary control power of } \\
\text { each generator (MW) }\end{array}$ \\
\hline REDBUD69 (bus 14) & 5.8 \\
ELM345\#1 (bus 28) & 0 \\
ELM345\#2 (bus 28) & 26 \\
SLACK345 (bus 31) & 36.2 \\
PEACH69 (bus 44) & 23.1 \\
CEDAR69 (bus 48) & 8.2 \\
BIRCH69 (bus 50) & 12.3 \\
PEAR138 (bus 53) & 21.7 \\
PEAR69 (bus 54) & 16.6 \\
& Total $=150 \mathrm{MW}$ \\
\hline
\end{tabular}


Because the recovery frequency is less than the allowable value, so the secondary control is implemented after the primary control. The spinning reversed power of the generators will be mobilized to perform the secondary control. In this case, the secondary control power is $15.5 \mathrm{MW}$. The frequency of the system after the implementation of the secondary control is shown in Figure 6.

Thus, after performing the secondary control, the recovery frequency is $59.57 \mathrm{~Hz}$ and has not yet returned to the allowed value. Therefore, the final solution is load shedding. Equation (7) is applied to calculate the minimum amount of load shedding power to recovery the frequency in allowable value.

$$
\begin{aligned}
& P_{L S \text { min }}=\Delta P_{L}-\left(\frac{\Delta f_{p}}{\beta}\right)-\Delta P_{\text {Secondary Max }} \\
& =1.5-\left(\frac{0.3}{0.00482 \times 60}\right)-0.155=0.3077 p u=30.77 \mathrm{MW}
\end{aligned}
$$

After calculating the minimum discharge capacity, the distribution of the layoffs at the loaded buses is done. The lay-off power distribution is based on the voltage electrical distance value between the ELM345\#1 generator and the load buttons. After calculating the minimum load shedding power, the load shedding distribution at the load buses is calculated. The amount of load shedding at load buses based on the voltage electrical distance between the ELM345\#1 generator and the load buses. Calculation steps at section 2.4 are applied to calculate the voltage electrical distance between the ELM345\#1 generator and the load buses.

The voltage electrical distance relationship between the ELM345\#1 generator and the load buses is shown in Figure 7. Observe Figure 7, which shows that the load buses nearer to the outage generator the lower VED; and the further to the outage generator, the greater the VED.

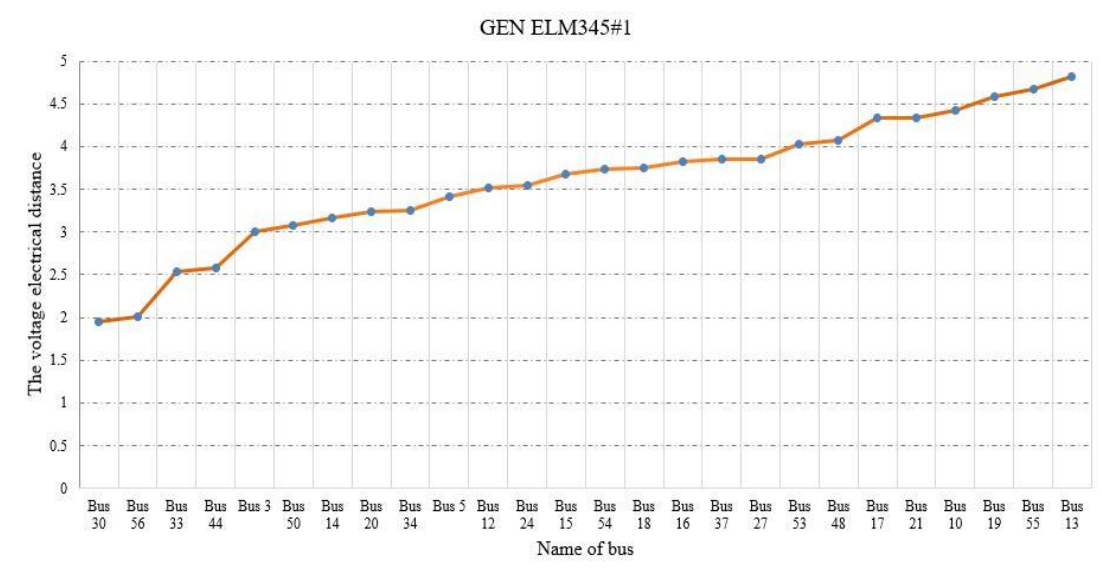

Figure 7. The voltage electrical distance between the ELM345\#1 generator and the load buses

The priority load shedding distribution for each load bus is calculated based on the following principle: The nearer the load buses from the generator outage, the greater the amount of shedding power. Equation (10) in Section 2.4 is applied to calculate the amount of disconnection power value at the load buses.

In order to compare the effectiveness of the proposed method, the load shedding method using under frequency load shedding relay is used to compare. The process of UFLS is implemented when the frequency reduces below the frequency setting threshold. The load is usually cut step-by-step based on the load shedding table that pre-designed based on the general rule and operator experience. These tables guide the amount of load that should be cut at each step depending on the decrease of frequency. These values are shown in Table 3.

The frequency and the rotor angle comparison between the proposed method and the UFLS method are presented in Figure 8. It can be seen that the proposed load shedding method has less the amount of shedding $(60.21 \mathrm{MW})$ than the UFLS. Here, the recovery frequency value of the proposed method is lower than the UFLS method. However, this value is still within allowable parameter and acceptable range $(59.7 \mathrm{~Hz})$. Especially, when considering the phase angle recovery time of the proposed method is equivalent to the UFLS method, although this method has less the amount of load shedding than UFLS method. This can

A voltage electrical distance application for power system load shedding considering ... (Le Trong Nghia) 
be explained by the fact that a large load at load nodes close to the generator are disconnected causing the phase angle to recover faster.

Table 3. The UFLS scheme using load shedding table [20]

\begin{tabular}{ccccc}
\hline $\begin{array}{c}\text { The steps } \\
\text { UFLS }\end{array}$ & $\begin{array}{c}\text { Frequency } \\
(\mathrm{Hz})\end{array}$ & $\begin{array}{c}\text { Time } \\
\text { delay }(\mathrm{s})\end{array}$ & $\begin{array}{c}\text { The amount of load } \\
\text { shedding (the percent of } \\
\text { total load) }(\%)\end{array}$ & $\begin{array}{c}\text { Total amount of } \\
\text { load shedding } \\
(\%)\end{array}$ \\
\hline A & 59.7 & 0.28 & 9 & 9 \\
B & 59.4 & 0.28 & 7 & 16 \\
C & 59.1 & 0.28 & 7 & 23 \\
D & 58.8 & 0.28 & 6 & 29 \\
E & 58.5 & 0.28 & 5 & 34 \\
F & 58.2 & 0.28 & 7 & 41 \\
J & 59.4 & 10 & 5 & 46 \\
\hline
\end{tabular}
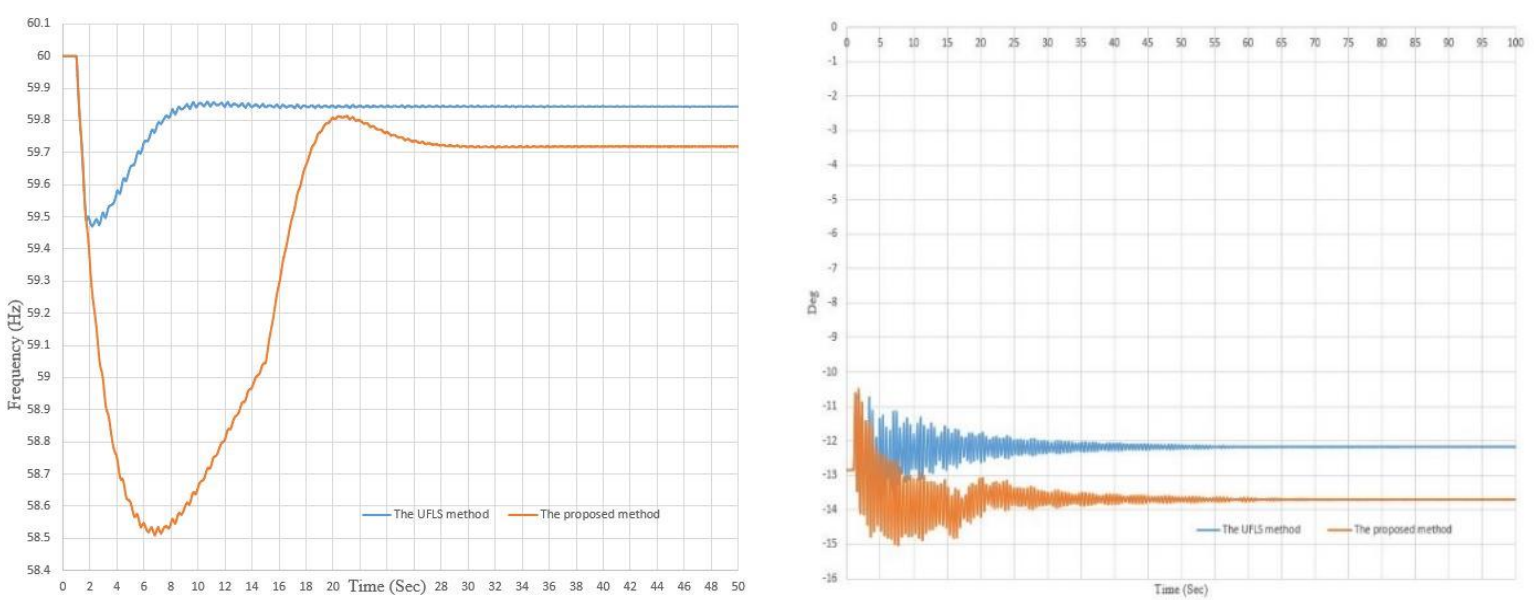

Figure 8 . The frequency and rotor angle comparison between the proposed method and the traditional method

\section{CONCLUSION}

A load shedding method considers to the primary and secondary control elements of the power plant to calculate the minimum amount of load shedding power and restore the frequency back to the allowable value. The proposed method ensures the frequency and rotor angle stability of the system in case of a severe generation-load mismatch. The selection of location and distribution of load shedding power at load buses are based on the voltage electrical distance concept.

The effectiveness of the proposed method has been demonstrated on a 9-machine, 37-bus system under voltage test cases. The performance of is found to be better than that of a conventional UFLS scheme. The test results show that the proposed method results in reduced amount of load shedding while satisfying the operating conditions and limitations of the network.

\section{ACKNOWLEDGEMENTS}

This research was supported by the HCMC University of Technology and Education.

\section{REFERENCES}

[1] R. M. Larik, et al., "A statistical jacobian application for power system optimization of voltage stability," Indonesian Journal of Electrical Engineering and Computer Science, vol/issue: 13(1), pp. 331-338, 2019.

[2] S. Weckx, et al., "Primary and Secondary Frequency Support by a Multi-Agent Demand Control System," IEEE Transactions on Power Systems, vol. 30, pp. 1394-1404, May 2015.

[3] Raghu C. N. and A. Manjunatha, "Assessing Effectiveness of Research for Load Shedding in Power System," International Journal of Electrical and Computer Engineering (IJECE), vol. 7, pp. 3235-3245, Dec 2017.

[4] G. Kabashi and S. Kabashi, "Review of under Frequency Load Shedding Program of Kosovo Power System based on ENTSO-E Requirements," International Journal of Electrical and Computer Engineering (IJECE), vol. 8, pp. 741-748, Apr 2018. 
[5] L. Sigrist, "A UFLS Scheme for Small Isolated Power Systems Using Rate-of-Change of Frequency," IEEE Transactions on Power Systems, vol/issue: 30(4), pp. 2192-2193, 2015.

[6] T. Amraee, et al., "Probabilistic Under Frequency Load Shedding Considering RoCoF Relays of Distributed Generators," IEEE Transactions on Power Systems, vol. 33, pp. 3587-3598, 2018.

[7] C. T. Hsu, et al., "Design of Adaptive Load Shedding by Artificial Neural Networks," IEE Generation, Transmission, Distribution, vol/issue: 152(3), pp. 415-421, May 2005.

[8] A. A. Sallam, and A. M. Khafaga, "Fuzzy Expert System Using Load Shedding for Voltage Instability Control," IEEE Large Engineering Con. on Power Engineering, Jun 2002.

[9] W. P. Luan, et al., "Genetic Algorithm for Supply Restoration and Optimal Load Shedding in Power System Distribution Networks," IEE Proceedings - Generation, Transmission and Distribution, vol. 149, pp. 145-51, 2002.

[10] G. A. M. H. Hajivar and S. S. Mortazavi, "Impact of Shunt FACTS Devices on Security Constrained Unit Commitment," International Journal of Applied Power Engineering (IJAPE), vol. 5, pp. 22-39, Apr 2016.

[11] P. Pinceti, et al., "Design criteria for a power management system for microgrids with renewable sources," Electr. Power Syst. Res, vol. 122, pp. 168-179, May 2015.

[12] K. Balasubramaniam, et al., "Energy management system for enhanced resiliency of microgrids during islanded operation," Electr. Power Syst. Res, vol. 137, pp. 133-141, Aug 2016.

[13] M. Moafi, et al., "Energy management system based on fuzzy fractional order PID controller for transient stability improvement in microgrids with energy storage," Int. Trans. Electr. Energy Syst, vol. 26, pp. 1-20, Feb 2016.

[14] P. Kundur, "Power System Stability and Control," First Edition, McGraw-Hill Inc, pp. 507, 1994.

[15] C. R. Balamurugan, "Three Area Power System Load Frequency Control Using Fuzzy Logic Controller," International Journal of Applied Power Engineering (IJAPE), vol.7, pp. 18-26, Apr 2018.

[16] A. J. Wood, et al., "Power Generation, Operation and Control," Third Edition, John Wiley \& Sons, Inc, pp. 473-481, 2014.

[17] A. Goikoetxea, et al., "Frequency restoration in insular grids using Ultracaps ESS," Power Electronics Electrical Drives Automation and Motion (SPEEDAM) International Symposium on, pp. 1280-1285, Jul 2010.

[18] L. Patrick, "The different electrical distance," In Proceedings of the Tenth Power Systems Computation Conference, pp. 542-550, 1990.

[19] J. D. Glover, et al., "Power System Analysis and Design," Fifth Edition, Cengage Learning, The 37 bus-9 generators test system (Ex.11.9), Available: https://www.powerworld.com/simulator-19-glover-sarma-overbyeedition-download, 2012.

[20] Florida Reliability Coordinating Council, "FRCC Regional Underfrequency Load Shedding (UFLS) Implementation Schedule, FRCC handbook,” Jun, 2011.

\section{BIOGRAPHIES OF AUTHORS}

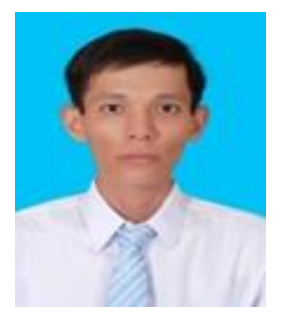

Trong Nghia Le received his M.Sc. degree in electrical engineering from Ho Chi Minh City University of Technology and Education (HCMUTE), Vietnam, in 2012. Currently, he is a lecturer in the Faculty Electrical and Electronics Engineering, HCMUTE. His main areas of research interests are load shedding in power systems, power systems stability, load forecasting and distribution network.

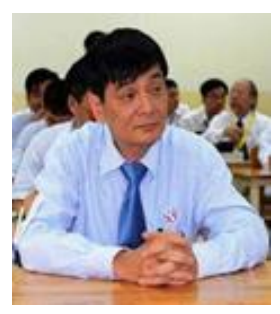

Quyen Huy Anh received PhD degree in power system from MPIE, Russia in 1993. Currently, he is a professor, lecturer in the Faculty Electrical and Electronics Engineering, HCMUTE. His research interests are modeling power systems, pattern recognition in dynamic stability of power systems, and artificial intelligence.

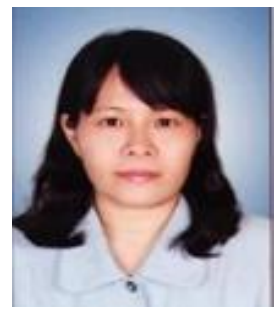

Phan Thi Thanh Binh received Ph.D. degree in electrical engineering from Kiev Polytechnique University, Ukraine in 1995. Currently, she is a Professor and lecturer in the Faculty Electrical and Electronics Engineering, HCMUT. Her main areas of research interests are power systems stability, power systems operation and control, load forecasting, data mining. 


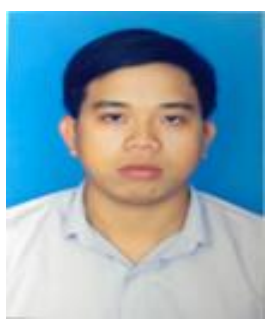

Nguyen Thai An received his Eng. degree in electrical engineering from Ho Chi Minh City University of Technology and Education (HCMUTE), Vietnam, in 2018. Currently, he is learning electrical master's degree in HCMUTE. His main areas of research interests are load shedding in power systems, power systems stability, and load forecasting and distribution network.

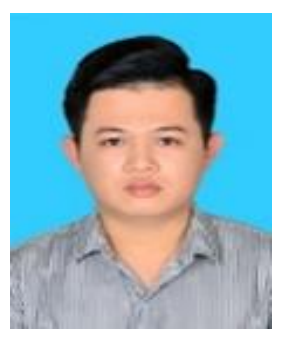

Pham Hong Hau received his Eng. degree in electrical engineering from Ho Chi Minh City University of Technology and Education (HCMUTE), Vietnam, in 2018. Currently, he is learning electrical master's degree in HCMUTE. His main areas of research interests are load shedding in power systems, power systems stability, and load forecasting and distribution network. 